\title{
CHINA: REGIONAL DISPARITIES IN POVERTY DISTRIBUTION
}

\author{
CHUNLI SHEN \\ School of Public Policy, University of Maryland, College Park, MD 20742, USA \\ HENG-FU ZOU
}

CEMA, Central University of Finance and Economics, Beijing, China

\begin{abstract}
China's remarkable poverty alleviation is quite uneven across regions in the last quarter of the century. It is important to explore why China has such huge disparity in poverty distribution in spite of overall dramatic economic growth and the vast improvement in per capita income. The aim of this paper is to fill the literature gap by focusing exclusively on the issue of regional disparities in poverty distribution in China. It finds an increasing concentration of the rural poor in south-western provinces and the urban poor in northern China. Behind the scene, political choices and public polices, particularly barriers restricting the flow of labor, and fiscal rules that provides the disadvantaged population and regions less access to the fruits of division of labour, have a critical impact on how the effects of endowment and geography play out in the country's poverty distribution. In efforts to fight against skewed poverty concentration and build a harmonious society, further policy actions are required to promote agricultural development and off-farm employment, enhance infrastructure investment in poor regions, lower fiscal disparities and promote equitable public services provision, and address the regressive inter-governmental fiscal system.
\end{abstract}

Keywords:

Poverty; income distribution; regional disparity; mobility; China; poverty

See http://www.worldscinet.com/dltc/03/0301/S0219871108000343.html 